\title{
Mulemba
}

Revista Angolana de Ciências Sociais

6 (12) | 2016

Sobre a sociedade e a cultura em Angola e alhures:

algumas reflexões de percepções sobre a realidade e múltiplas experiências

\section{Fundamentos da ekula no poder tradicional mundombe}

Fundamentals of ekula in traditional Mundombe power

\section{Armindo Jaime Gomes}

\section{OpenEdition \\ Journals}

\section{Edição electrónica}

URL: http://journals.openedition.org/mulemba/1087

DOI: 10.4000/mulemba.1087

ISSN: 2520-0305

\section{Editora}

Edições Pedago

Edição impressa

Data de publição: 1 novembro 2016

Paginação: 179-202

ISSN: 2182-6471

\section{Refêrencia eletrónica}

Armindo Jaime Gomes, «Fundamentos da ekula no poder tradicional mundombe», Mulemba [Online], 6

(12) | 2016, posto online no dia 30 setembro 2018, consultado o 26 janeiro 2021. URL: http://

journals.openedition.org/mulemba/1087 ; DOI: https://doi.org/10.4000/mulemba.1087 


\title{
Fundamentos da ekula no poder tradicional mundombe
}

\author{
Armindo Jaime Gomes ${ }^{*}$
}

\begin{abstract}
Resumo: Este artigo foi escrito a partir de uma súmula de dados orais recolhidos entre 1997 e 2005 e procura analisar a realidade sociocultural e etno-histórica ndombe do Dombe Grande, localidade situada no sul litorâneo de Benguela. No início, a colecta de materiais nos trabalhos de campo tinha por objectivo conhecer a realidade em que se processavam as metodologias educacionais não-formais numa perspectiva freireana, ao mesmo tempo que do ponto de vista etnológico se procurava identificar melhor o Mundombe, tendo em conta o velho pressuposto apontado por distintos estudiosos e investigadores, cujas propostas de classificação intregravam essa comunidade na cadeia Ovimbundu. A excepção contrária à regra desse ponto de vista se deve a Ana de Sousa Santos $(1963 ; 1965)$ e Ruy Duarte de Carvalho (1997), que defenderam tratar-se de um complexo sociocultural do conjunto Helelo, ainda que, por confirmar. Para assegurar essa tese, o presente texto faz a descrição de uma cerimónia tradicional sobre a ekula, instituição de natureza político-religiosa observada em 1999, sem contudo poder sustentá-lo com referências bibliográficas de estudos efectuados anteriormente sobre este assunto.
\end{abstract}

Palavras-chave: Instituição tradicional endógena, ekula, Ohoma y'Ekula, complexo socioculturalm, complexo sociocultural Helelo, cadeia Ovimbundu.

\section{o. Introdução}

17 de Novembro de 1999. Entardecia. Compareceu junto de nós Aníbal Barbosa, então activista do programa de educação cívica e direitos humanos, para anunciar que o Ohoma y'Ekula ndombe acabava de convocar a realização da ekula, a ter lugar algures na periferia da comuna do Dombe Grande, no final da semana seguinte. Pela primeira vez ouvimos falar da ekula e isso graças a um dos sentinelas-informadores mobilizados entre activistas do programa

* Docente da cadeira de História de Angola na Academia Militar do Exército (Benguela) e investigador independente. 
educacional não-formal acima indicado, programa esse que se desenvolvia junto dos refugiados do interior assentados na aldeia do Luacho e na sede da comuna do Dombe Grande.

A ideia de criar o núcleo de sentinelas-informadores entre membros das comunidades do Dombe Grande, respondia à necessidade metodológica do desenvolvimento comunitário no que concerne à colecta de informações sobre as dinâmicas quotidianas do âmbito sociocultural ndombe, mormente as relacionadas com o funcionamento das instituições tradicionais endógenas, normalmente de acessos limitados aos agentes externos, enquanto actores não governamentais com pouca simpatia nutrida pelo poder público.

No âmbito das nossas actividades, havia a necessidade de se efectuar uma penetração educacional dentro das comunidades de referência. No entanto, não obstante ao seu característico sincretismo sociocultural, o Dombe Grande era um espaço impermeável. Aos olhos dos agentes externos, a região nutria um perfil institucional de «sociedade secreta», razão porque externamente sempre fora rotulada por «região de feitiços».

Com base neste pressuposto e a luz do presente trabalho, procuramos sustentar o posicionamento de Ana de Sousa Santos e Ruy Duarte de Carvalho documentando e estudando a ekula, uma instituição endógena fundamentada no poder da autoridade tradicional ndombe, tal como o são igualmente ekwenje, ohovya e okuyanga, respectivamente. Para isso valemo-nos essencialmente dos dados e do consequente tratamento das informações orais, recolhidos antes e depois das observações que nos foram permitidas no decurso de dez dias ininterruptos.

\section{Ekula ou poder iniciático ndombe?}

Uma das características fundamentais que diferenciam o Mundombe da grande parte dos povos seus vizinhos, incluídos os Ovimbundu predominantes na região (ARJAGo 1999), reside na realização da ekula. Trata-se de uma instituição multifacética, social e politicamente congregadora, cuja envergadura supera toda e qualquer instituição tradicional endógena ndombe. Multifacética porque na sua vigência comporta manifestações relativamente aos poderes político, económico, e sobretudo, religioso (MARTINEZ 2007), tornando-se o momento jubiloso e mais solidário, constitui motivo 
de grande festival comunitário com participação ilimitada e realiza-se uma vez em cada geração, num período compreendido entre 25 anos (Gomes 2007). Equivale dizer que a instituição que vamos descrever reúne todos indivíduos que reivindicam a identidade cultural ndombe, pelo menos 4 vezes em cada 100 anos. Esta realidade não se encontrou referenciada nas fontes de acesso, não se conhece fora do Dombe Grande, particularmente no planalto e é uma manifestação exclusiva do Mundombe, com participação aparentemente passiva do Mukwandu, por haver consciência deste último de que o valor aqui aludido não é de sua pertença. ${ }^{1}$

No olhar de um agente externo (CHAMBers 1995), a ekula é para o Mundombe o instrumento de gestão comunitária, relativamente ao poder político tradicional endógeno em linha recta que reparte e organiza a comunidade em quatro categorias, sustentadas pelo pilar matrilinear em que todos os Vandombe do sexo masculino são membros em pleno direito desde que tenham participado do ekwenje (plural: akwenje).

No seu todo, a ekula estrutura a comunidade política ndombe de forma ascendente em quatro categorias, das quais três em pleno exercício de cidadania (jovens, adultos e mais velhos):

Figura 1. Estruturação da ekula

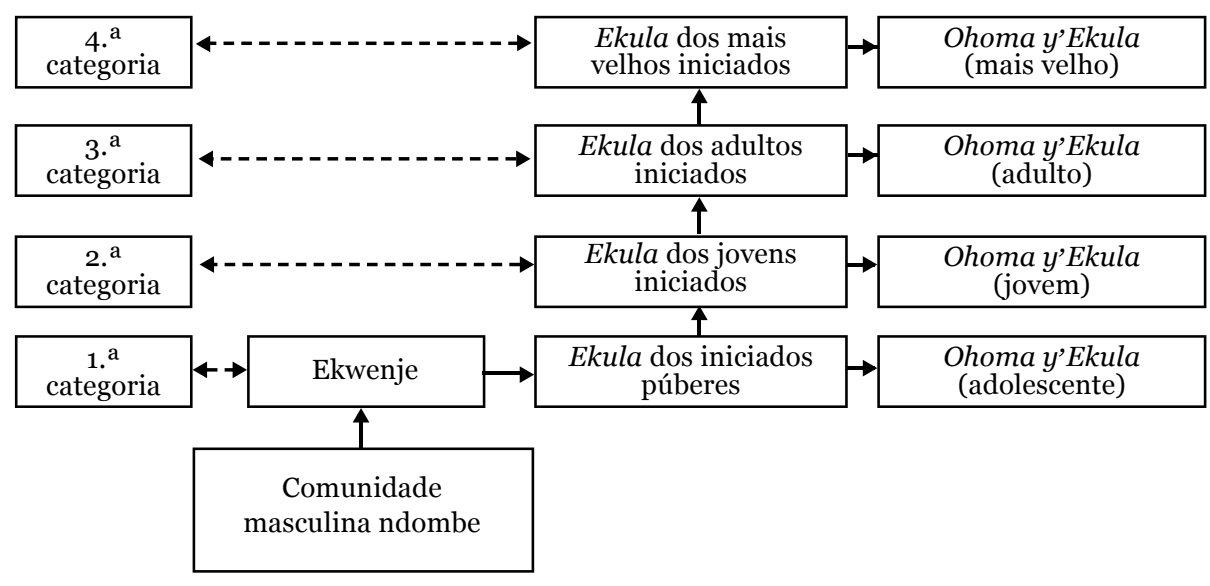

Fonte: Autor

1 Assunto que reservamos para um trabalho posterior acerca da identidade cultural kwandu. 
A realização da ekula, com a participação do primogénito do Homa y'Ekula, envolvendo os participantes das akwenje antecedentes, legitima o surgimento da nova ekula, detentora do poder endógeno da autoridade tradicional, cujo testemunho é entregue da mais velha ekula e daí em diante esta passa ao passivo. Na mesma escala promocional, a última ekula transita para a categoria da ekula jovem e esta para a ekula de adultos que, por sua vez, passa para a dos mais velhos e assim, os últimos, os da ekula mais velha anterior desaparecem da ordem da escala estrutural.

Trata-se de um cerimonial realizado em módulos de rituais, permitindo a transição do Mundombe adolescente, caracterizado como sendo criancinha dependente da mamã, imaturo, que não crescem, impuro para uma mulher decente, marginal (CREMA s.d.), ao Mundombe cidadão (Altuna 1985). Mesmo não sendo uma comunidade com envergadura estrutural como é o caso de outras realidades socioculturais Helelo (EsTERMANN 1959; 1983), a moral comunitária limita o meio de intervenção social do Mundombe de sexo masculino, que não tenha apreendido os rudimentos mais elementares da ekula ainda que tenha frequentado o ekwenje, ou simplesmente, seja circuncidado (DufF 1949), independentemente dos métodos aplicados e dos lugares frequentados,

a) não desposam mulheres da identidade cultural ndombe (EsTERMANN 1944; 1983);

b) são excluídos das mais importantes decisões comunitárias (GoMES 2007);

c) ficam expostos fora do ocoto ${ }^{2}$ (GuEBE 2003).

Em virtude destas cerimónias serem realizadas na base de intervalos muito longos (de 25 em 25 anos, como vimos), observa-se uma movimentação jamais vista de adolescentes e jovens que, partindo 182 em busca da honra e da dignidade e sem medirem custos, estabelecem extraordinária concorrência, o que torna a imagem deveras surpreendente. Aderentes vindos das mais longínquas localidades fora da comuna do Dombe Grande e da província de Benguela, particularmente a juventude das distintas profissões e ocupações consideram válida e conquistadora do seu espaço participando.

2 Leia-se otchoto. Espaço com funções similares ao njango. 


\section{Delimitação institucional da ekula}

A realização da ekula que vamos descrever, foi despoletado no momento em que o Ohoma y'Ekula convocou o encontro da nova ekula (Gomes 2007). A figura do Homa y'Ekula é parte da autoridade tradicional endógena ndombe (ARJAGO 2002), sendo detentora de poderes dinásticos que em terra representam a comunidade ndombe, subentendida entre os ancestrais (SANTOS 1962), isto é, os não-vivos e os membros vivos. É o representante da mais alta hierarquia ndombe, comunidade conhecida por Vandombe, assim como pelas demais comunidades localizadas na região, sem que haja relação com o poder oficial que não o aceita, sendo por isso ignorado.

Vendo-se em pleno exercício da sua função, herdada dos seus antepassados, o Ohoma y'Ekula aglomerou a comunidade na data e local previamente anunciados, junto de um espaço mais ou menos hierofánico (ELIADE 2006) que corresponde com ao elombe ou «templo sagrado» (op. cit.), disposto próximo da sua residência.

A convocatória é efectuada porque o primogénito do Homa y'Ekula completa a idade que lhe permite participar no ekwenje (Estermann 1944, 1983; Altuna 1985). Em função do preceituado, participam do ekwenje os adolescentes em idade púbere, cujos limitem dependem unicamente do desenvolvimento biológico manifestado por cada interessado (cf. Altuna 1985).

Sabe-se que em tempos idos e por bonança, esta instituição era susceptível de se realizar durante um período longo, podendo atingir pelo menos dois anos consecutivos. Hoje, possivelmente resultante da implantação na região de infra-estruturas agro-industriais de tipo colonial e consequentemente da posterior deterioração social e económica, esse longo tempo foi sendo paulatinamente reduzido e hoje ocorre num período limitado a dois meses, e isso estando ainda dependende das condições que justifiquem a sua realização, sem contudo ser possível efectuarem-se deslocações muito afastadas da localidade e do local escolhido (Altuna 1985; Duff 1945). E mais, a cerimónia acontece numa altura que tudo escasseia e o impacto da guerra do interior nem sempre permite que os Vandombe a realizem longe do litoral, na forma como desde sempre a idealizaram e com a liberdade desejada pela comunidade.

Por sua natureza, o ekwenje (DuFf 1945) é a instituição economicamente exigente e, por característica histórica bantu, o período 
normal da sua realização é o menos produtivo, motivo porque acontece depois das colheitas, por duas razões:

a) Grande parte dos participantes é oriunda das forças produtivas;

b) a dieta alimentar, exigida à fartura, é baseada fundamentalmente no gado bovino e do milho, o cereal principal da sua dieta.

O grau de exigência socio-económica eleva-se a partir da obrigação dos candidatos terem de ser acompanhados por educadores (Santos 1969; Altuna 1985), geralmente irmãos consanguíneos das suas progenitoras, que se constituem como os seus tutores e verdadeiros pais sociais (ARJAGo 1999); além disso, há ainda que alimentar os membros da comissão organizadora e os outros membros que compõem o sistema do poder da autoridade tradicional endógena, multiplicando assim a quantidade dos envolvidos, enquanto participantes activos (cf. SANTOS 1969), necessários para garantir a efectivação com êxito dos objectivos perseguidos pela referida instituição.

Tal como foi no período pré-colonial (EsTERMANN 1944; 1983), e mesmo tal como foi antes da independência de Angola em 1975 (Gomes 2007), o normal é que a cerimónia ekwenje seja realizada anualmente, tendo em conta as condições logísticas muito próprias, ligadas à abundância das precipitações para fins agro-pecuários e à produtividade comunitária, particularmente do gado. O prolongamento do tempo e as condições exigidas naquela altura prendiamse com o facto de tratar-se de uma escola masculina (cf. AltunA 1985) de tipo «espartaniana», na qual os adolescentes apreendiam as experiências colectivas dos adultos, resumidas nos conhecimentos teórico-práticos relativos aos conteúdos etno-históricos, etnosociológicos, etno-religiosos, etno-medicinais, educação cívica, a pedagogia e a eloquência, a higiene e educação sexual, a filosofia e psicologia, a ética e a moral, etc., aos treinamentos práticos como a natação, música, coreografia, pesca, caça, escultura, etc. (id., ibidem), ao desporto, educação militar, tudo isso tendo como objectivo fundamental, o de moldar a estrutura mental do cidadão (cf. Altuna 1985), passando pela criação de espírito de sacrifício e de partilha, irmandade e camaradagem, ajuda mútua, destreza, através de métodos práticos rígidos e orais, baseados em provérbios e máximas, narrativas, canções satíricas e épicas, etc., etc. (GonçALVES 2001). 
Não obstante as severas restrições impostas pelo regime colonial, com o advento da proclamação da independência de Angola, a partir de 1976 e em seguida, o cumprimento do programa curricular do ekwenje foi reduzido e tornou-se deficitário devido a vários factores, nomeadamente a guerra, entretanto acentuada com a destruição do parque industrial ${ }^{3}$ do Dombe Grande, a ocorrência de sistemáticas estiagens, cíclicas inundações e cheias do vale do rio Kupololo. Do prazo de um ano, as realizações da ekula passaram para uma semana a contar depois da terapia da ablação dos prepúcios dos candidatos do ekwenje, que ainda podem acampar durante dois meses. A grande mudança reside no facto de que durante $o$ sarar das feridas, os adolescentes muniam-se de aulas teóricas orais para depois passarem ao intenso trabalho de preparação física, sem a aplicação da rigidez metodológica que era característico durante o período pré-colonial.

Não obstante as mudanças resultantes das crises pós-independência e consequentes mudanças nas estruturas tradicionais endógenas, com o fluxo migracional do interior para o litoral, contrariamente ao observado nas comunidades identificadas por outros grupos etnolinguísticos da região, no decurso do ekwenje o Mundombe não aplicava todo o seu programa (cf. Gomes 2007). Parte das actividades normais reservavam-se para a realização da ekula com a participação do primeiro filho do Homa. As realizações periódicas das akwenje, tinham outrora significado e valor político participando o primogénito do Homa y'Ekula que compreensivelmente aparecia uma única vez e a sua participação compreendia a fase da puberdade, pelo que aos adolescentes anteriores obrigava-se a participarem no ekwenje do primogénito do Homa y'Ekula, e isso com o intuito de legitimarem a passagem do testemunho da autoridade política matrilinear, isto é, do pai social ao filho biológico da irmã e a todos os adolescentes que o antecederam, incluindo os seus coetâneos, que formavam uma classe socio-política designada ekula (id., ibidem).

Enquanto o primogénito do Homa y'Ekula em idade púbere, filho biológico da irmã, não existir, os adolescentes Vandombe participantes do ekwenje reservam parte dos programas curriculares

3 Referimo-nos a antiga Companhia do Assúcar de Angola, que após a independência foi nacionalizada e mudou de designação para Açucareira 4 de Fevereiro, posteriormente destruída em consequência da guerra. 
emprestando conteúdos para a realização da ekula. O facto de aquele participar como adolescente justifica a realização da ekula seguinte no trecho de tempo compreendido entre os 25 anos, o suficiente para o nascimento de um filho na linhagem matriarcal real ndombe cuja sua participação no ekwenje serve de sanção de todos akwenje antecedentes. Factos são hoje conhecidos segundo a qual a herança transitou pela linha patriarcal (patrilinear) mas, caso no período indicado o primogénito esperado do Homa y'Ekula não exista, ou tenha nascido do sexo feminino, cabe apresentar o primogénito de uma das irmãs do Homa y'Ekula na ordem matrilinear (GoMEs 2007).

\section{Lógica do funcionamento da ekula}

Do ponto de vista da ordem funcional da ekula, partindo dos dados recolhidos depois do alerta de um dos sentinelas-informadores anteriormente referidos, foi possível reordenar a informação acolhida através dos passos seguintes:

\section{Primeiro passo:}

Confirmada a informação sobre a existência de um primogénito do Homa y'Ekula (um jovem de 23 anos) depois da última ekula, ocorrida em 1976; o Ohoma y'Ekula (mais velhos) reúne olohoma vy'Akula ${ }^{4}$ dos jovens, adultos e mais velhos com os respectivos vakesongo ${ }^{\mathbf{5}}$ para avaliarem as condições económicas preexistentes e, em caso favorável, determinarem a convocação da comunidade ndombe para a realização da ekula dos púberes, que é antecedida do ekwenje, que é feito sob patrocínio dos membros das akula dos jovens e adultos, que contribuem com as ofertas de gado em quantidade justificável para o sacrifício durante o cerimonial.

Importa aludir que o touro, principal elemento e factor de coexistência da economia doméstica tradicional, também se torna uma instituição ndombe, pelo que caracteriza o ambiente económico da cerimónia da mais elevada consideração comunitária, pois a quantidade sacrificada determina o status social quer colectivo, quer individualmente de cada contribuinte.

4 Plural de Ohoma y'Ekula.

5 O mesmo que Vakwelombe, conselho de assessores do Ohoma y'Ekula. 


\section{Segundo passo:}

Sob a liderança do seu Homa y'Ekula e dos respectivos vakesongo, a ekula jovem reúne distribuindo-se pelos bairros e aldeias, num raio de cerca de 30 quilómetros, para uma mobilização abrangente e indiscriminada, o monitoramento da criação das condições e a preparação logística, logo que os iniciados do ekwenje, entre filhos, contemporâneos e coetâneos do primogénito do Homa y'Ekula jovem, completam sete semanas de estadia no ocombo. ${ }^{6}$ Nesta altu$\mathrm{ra}$, a comunidade expectante por um acontecimento raro, difícil de acontecer e pouco conhecido, nada mais se pode ouvir em toda a comuna do Dombe-Grande, senão a propagação da notícia da realização do evento.

\section{Terceiro passo:}

São mobilizados os cidadãos, adolescentes e jovens do sexo masculino desde que tenham sido circuncidados no período limitado entre a última realização, neste caso a cerimónia de 1976 e a ekula convocada no ano em referência, isto é, em 1999, com a qual se identificam, e que tendo previamente escolhido um lugar, ao meio do dia, reúnem-se preparados para o início da partida. Com pequenas trouxas de bens privados presas sob bengalas penduradas sobre um dos ombros, perfilando em coluna indiana partem ao encontro do ocombo, onde são aguardados pelos iniciados do ekwenje, com vista serem integrados no plano dos ensaios da ekula. A presença destes é obrigatória, pois tendem para a uniformização dos rituais constituintes da geração e a preparação do encerramento do ekwenje, por fazer-se coincidir com a institucionalização da ekula mais nova.

Quarto passo (primeiro dia):

A entrada lotante no ocombo é feita em longa fila indiana, entoando com alegria canções épicas recheadas de sátiras. São recebidos pelos iniciados do ekwenje com um coro de assobios orquestrados e gritos desordenados de boas vindas. No geral, 60 dias mais ou menos, um grupo de púberes escolhe residir num espaço bucólico, tosco no olhar de agente externo, com todos os pressupostos rudimentares próprios de uma cultura natural, em busca da personalidade própria

6 Leia-se otchombo. Designa o mesmo que kilombo em olundombe, a língua dos Mundombe. 
que a comunidade lhes reserva. São no seu todo menores finalistas de uma escola secular irrepetível, cujas lições culturais e identitárias dela apreendidas marcam o resto de suas vidas. Calculados em mais de três centenas, dos 7 aos 30 anos de idade, organizados em estruturas de pelotão por idades, os participantes começam com a primeira fase de ensaio da dança característica, designada muito justa mente por a dança da ekula, até ao entardecer altura de um intervalo para jantar e, em seguida, darem continuidade ao programa que inclui outras actividades programadas para o resto da noite afora.

Quinto passo (segundo dia):

O segundo dia passado do ocombo amanhece e prolonga-se com os exercícios intensivos relativos à dança ekula. Porém, depois de reforçada a refeição de carne dos touros sacrificados feita em conduto do pirão de milho, pouco antes de entardecer, os iniciados espalham-se pelas estepes a procura de angwengwe, um tipo de rama assim conhecido para confeccionar a vestimenta de gala. Uma peça uniforme da cintura, como se de um saiote longo se tratasse e um chapéu, de similar confecção, arruma-se para cobrir por inteiro a cabeça, excepto a parte superior. Por detrás, sobram-lhe palas decaídas pelo pescoço descobrindo a face. O uniforme ora descrito serve para treinamentos posteriores que se prolongam ao terceiro dia tornando o momento mais difícil da jornada, pois a capacidade de resistência até ao dia seguinte reduz em função das idades para a grande parte dos iniciados cujo sacrifício faz-se por se tratar de ritual exclusivo no resto da vida.

\section{Sexto passo:}

Na madrugada do terceiro dia, sem que sejam espiados por eventuais olhares profanadores, organizados e silenciados em fila india188 na, todos participantes vão ao ritual banho junto da lagoa de Civangulula ${ }^{7}$ localizada ao sul de Kangengo, muito próximo da ponte de acesso ao Dombe Grande e, no regresso, abandonam o ocombo desmantelando-o com queimadas de tudo quanto foi utilizado durante

\footnotetext{
7 Leia-se Tchivangulula. Entretanto, esta lagoa viria a desaparecer tendo aí sido instalada a primeira ponte da estrada de Benguela para o Dombe Grande.
} 
a estadia cerimonial e agora achado inútil, incluindo as vestimentas de treinos por eles confeccionadas.

\section{Sétimo passo:}

O sétimo passo descreve os exercícios integrais do quarto dia predominado pela execução cénica da ekula, intervenção dedicada ao juramento público com acesso livre de convidados, familiares, interessados, momento reservado para apresentação do Homa y'Ekula adolescente que, mesmo conhecido, todos almejam ver. Neste dia é perfilada a manada de touros dedicadas para o sacrifício, animais esses que terão sido doados como oferendas de honra em quantidades variadas, segundo a capacidade de cada contribuinte.

Nesse momento fez-se também a demonstração da envergadura da oferta do organizador, o Ohoma y'Ekula mais velho, agora identificado por Civela ${ }^{\mathbf{8}}$ Segunda. Num ano de intensa fome com mais de vinte mil famílias vivendo sob auspício da comunidade internacional, dez, foi o total de touros deduzidos do curral deste membro da autoridade ndombe que, nessa ocasião, equivaliam a cinco mil dólares norte-americanos no mercado local. A oferta caracteriza a importância que o Mundombe dá ao touro enquanto instituição e à própria ekula pois, numa região cadastrada pelo Programa Alimentar Mundial (PAM) das Nações Unidas, um agente do poder da autoridade tradicional endógena acabava de oferecer religiosamente em 1999, ao seu neto entronado como o terceiro na linha de sucessão, aquilo que não daria a qualquer custo à comunidade para sobreviver.

O antigo elombe é agora o palácio que capitaliza a ekula junto da residência do Homa y'Ekula Civela Segunda que em 1976 passou parte do testemunho ao seu primogénito e desta vez, pela mesma razão, testemunha a ascensão do neto.

Quatro líderes hereditários em linha directa das quatro gerações, rodeados pelos respectivos vakesongo, permanecem religiosamente num único ocoto (GuEBE 2003) acompanhando os rituais tradicionais a acontecer em série por todo o pátio:

1) O Ohoma y'Ekula avô, que entronizou o seu filho em 1957 (fonte: Autor. Uma esquadra da ekula dos pais);

8 Leia-se Tchivela. 
2) O Ohoma y'Ekula pai, entronizado em 1957, actual representante legítimo da comunidade ndombe no Dombe Grande;

3) O Ohoma y'Ekula filho, entronizado por aquele em 1976, sem direito ao pleno exercício do poder, enquanto o pai estiver em gozo dos seus direitos comunitários;

4) O Ohoma y'Ekula neto, que no final do juramento desta ekula vai assenhorar-se da autoridade do seu pai herdeiro do avô, mas o exercício pleno só acontece quando cessar o direito de seu pai ainda em guarda, da cessação das responsabilidades do avô.

Figura 2. Orquestração rítmica de um ritual

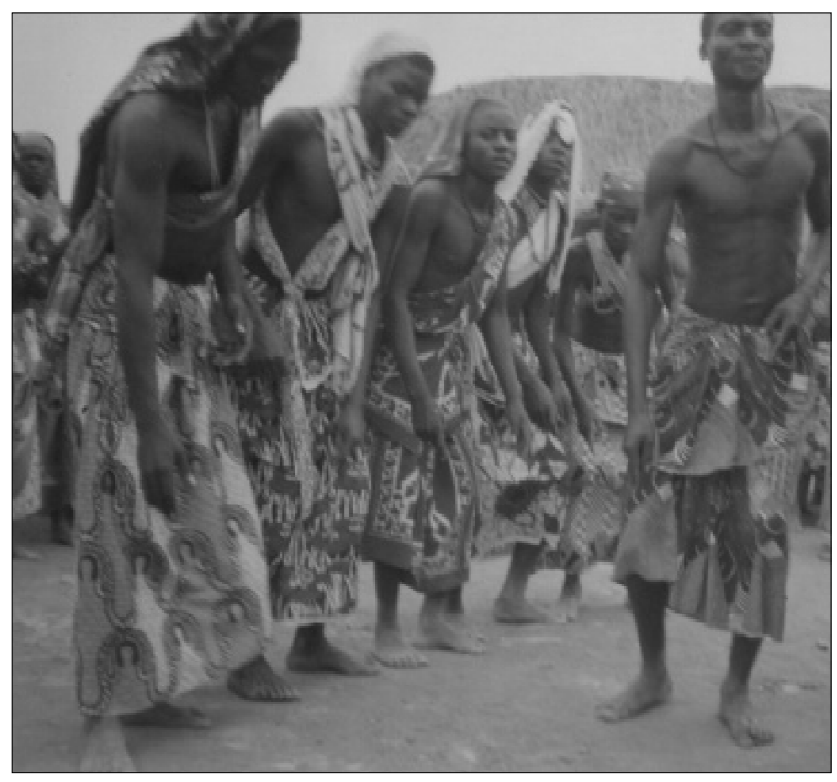

Fonte: Autor

À excepção do avô, que é o representante supremo de todos os vivos e ancestrais vandombe, cada um dos citados é líder legítimo no círculo da sua geração.

Em suma, o quarto dia acaba por se tornar o ponto culminante da ekula. As quatro gerações encontram-se e trocam experiências por meio de uma orquestra rítmica de rituais invulgares de sucessão político-religiosa, pressupondo o exercício do aprendizado de gestão comunitária. Neste contexto em que o conjunto de instituições actua em simultâneo, sem intervalos visíveis, durante uma semana torna-se muito difícil de entender o fluxo interactivo nas ocorrências múltiplas e diferenciar os tipos de relações que acontecem 
neste trecho de tempo em que os acontecimentos exercidos por vários grupos em forma de série e módulos, são irrepetíveis, salvo na ekula a ser convocada, eventualmente depois do ano 2019.

\section{Elombe, o núcleo de inteligência do poder ndombe}

O sentido etimológico de elombe, enquanto instituição do poder da autoridade tradicional endógena, não foge do que é característico noutros grupos etnolinguísticos de Angola, com comparação directa aos Ovimbundu (DAvid 1997; ArJaGo 1999). É o palácio (ARJAGO 2002), o paços. Outrossim, estruturalmente, diferencia-se sobremaneira dos exemplos atrás ditos, por corresponder às características de comunidades de economia fundamentalmente pastoril, respondendo ao meio ecológico onde se encontra. Além do funcionamento orgânico, compreendendo a uma hierarquia clara, obedece a uma estrutura de arquitectura simplesmente tradicional. Uma edificação de topo cónico e superfície arredondada com um orifício em vez de uma apertada entrada de acesso, de paus-a-pique, palha em volta e sobre o tecto. Pelo tamanho não alberga, no seu interior, mais de cinco pessoas sentadas, nem permite estarem mais de três pessoas adultas de pé. Em volta do fogo perpétuo, alojado no centro da superfície interna do elombe, localizam-se sentados os Olohoma y'Akula, mantendo a chama acesa como símbolo da integração da comunidade ndombe em torno de uma única autoridade (GonçALVES 1984).

A primeira vista a entrada parece livre por permanecer aberta mas torna-se vedada aos presentes excepto os membros da ekula dos mais velhos. Em posição mais ou menos discreta, encontra-se de vigia o Ohoma y'Ekula avô ladeado por dois vakesongo em escala como se de soldados de guarda de honra se tratasse. A quantidade destes varia a depender da demanda comunitária da circunscrição do poder da autoridade administrativa do Homa.

A cinco metros da porta do elombe institui-se ocoto, de estrutura rudimentar própria de criadores (cf. GuEBE 2003) baseado em pedras fixas perfiladas em duas posições viradas uma à outra. A posição que se encontra defronte da porta do elombe e, a maior por extensão, em forma de um meio arco, com duas filas juntas de pedras, é a de maior representatividade e nela sentam-se cerca de 
20 membros voluntários da ekula do Ohoma y'Ekula pai. A posição oposta, porque ambas são separadas simplesmente pelo fogo perpétuo aceso a partir do interior do elombe, é, normalmente, a mais pequena. $\mathrm{O}$ seu formato é também de um meio arco constituído por uma fila de pedras virada para a porta do elombe. Detrás desta fila de pedras, servindo de banco longo, encontramos um espaço aparentemente livre, com cerca de dois metros quadrados cobertos de troncos arrumados com palha por cima. O referido espaço designado por elisululu na língua olundombe, querendo dizer copa ou logística, serve de mesa para colocar a carne dos animais sacrificados.

Ocoto ora descrito (cf. Estermann 1949, 1983; GuEbe 2003), é uma outra instituição sociocultural independente do elombe por este estar conotado com a vida político-religiosa (MARTINEZ 2007) e limitado aos Olohoma vy'Akula e os Vakesongo. Na sua composição orgânica ocoto é constituído por conselheiros e pais dos membros da ekula dos filhos com acesso ainda limitado antes do juramento a realizar-se no final do último dia.

No meio do ocoto fica colocado um ongalo 9 para o depósito público dos proventos proveniente das multas resultantes das infracções cometidas pelos presentes, particularmente por causa do excesso de consumo de ocimbombo ${ }^{\mathbf{1 0}}$ de que provém a embriaguez que conduz às acções marginais como ofensas e furtos, além de punições aos mancebos atrasados nas paradas, faltosos das planificações. Aos ofendidos reserva-se o direito de propor o valor da multa, partindo de dinheiro à espécie que atinge o valor de touros de grande porte, que se revertem a favor da ekula.

Não muito distante, do ocoto e muito encostado ao elisusulu, constrói-se o ocimpanji. ${ }^{11}$ Este é um conjunto de troncos espetados em meia altura como se fosse pequena muralha de paus-a-pique, com cerca de um metro de cumprimento, onde simbolicamente são pendurados todos os cornos dos touros sacrificados permanecendo 192 ali até o tempo dar conta deles. Até lá, a quantidade dos cornos ilustra a envergadura económica da cerimónia para quem passar por aqui. Em cinco dias e noites programados, confirmamos o sacrifício de 48 touros, sem ter em conta a quantidade de caprinos e suínos,

\footnotetext{
9 Artefacto de palha. Balaio.

10 O mesmo que kimbombo.

11 Leia-se otchimpandji.
} 
animais de caça e aves de toda ordem. A esta altura um touro pesa no bolso de um citadino recorrente do mercado do Dombe Grande, \$500,00 USD, o suficiente para calcular-se o investimento mínimo da realização da ekula ndombe. Tratando-se de uma instituição pouco frequente, os cornos servem de relíquias comunitárias para certificar-se da realização do evento.

Uma outra instituição de relativa importância que aparece no mesmo cenário é o elisululu constituído por conselheiros da última geração, parte de aderentes ao ocoto, sendo pais dos mancebos na guarda do juramento, cuja função consiste na organização e manutenção da logística do cerimonial, cabendo-lhes acompanhar todos os passos dos seus filhos até ao último momento. Comportando-se como agentes do protocolo, na categoria de servidores da ekula, distinguem-se pelo porte de omutapi, designação da língua olundombe, também conhecido por ohutapi, dito da língua olukwandu, uma pulseira colocada no braço esquerdo feita de ouhipa, designação de fibras vegetais trançadas com fitas de couro fresco extraído das cabeças dos touros sacrificados.

Os servidores da carne fervida ou assada, os portadores de ohutapi, tomam a designação de vakwamutapi e no seu exercício apoiam-se de alguns utensílios de cozinha apropriados para estas cerimónias e que se conhecem por matemba, eholo e etumba, na língua olundombe, ou ociselo ${ }^{\mathbf{1 2}}$ entre os falantes do olukwandu. Com estes utensílios escoam das panelas, carregam e distribuem a carne a todos os presentes começando pelos membros da ekula dos filhos para terminar com as famílias acampadas, sem intervalos, deixando que os consumidores desistam pela fartura. Entretanto, dificilmente seria percebida a discriminação de ordem hierárquica da distribuição da carne aos presentes. Pronto a consumir, o touro é distribuído segundo as suas partes com valores interpretados em função das categorias e de classes beneficiárias. Nem todos têm acesso à carne da parte da cabeça, do peito, das coxas, a miudeza, por exemplos, por estar tudo direccionado.

Um aglomerado de cerca de dez mil espectadores de ambos sexos e todas as idades organizado por famílias acampadas há cinco dias, com mais de três centenas de mancebos da ekula, dispersa-se pelo pátio afora sobre as montanhas, debaixo do arvoredo entre os

\footnotetext{
12 Leia-se otchisselo.
} 
arbustos com pequenas cozinhas familiares onde preparam os seus manjares privados. Aqueles assistem, estes executam as várias instruções institucionais que se manifestam em simultâneo entre as distintas akula constituindo classes diferenciadas pelo porte externo uniformizado em cada uma delas.

Distinguem-se num ambiente de bastante cor reflectiva desde os trajes de gala apresentados quer por grupos, quer individualmente; - um lenço de cabeça que parte dele vai ao encontro dos ombros, duas peças de pano cruzadas pelos ombros, isto é, dos dois ombros e são presas por um nó debaixo de cada braço. Da cintura, uma outra peça de pano envolve a parte frontal até os joelhos enquanto outra por detrás cobrindo as nádegas e o resto do corpo até aos tornozelos presas por um cinturão vegetal, ao que chamam de eponda, ${ }^{\mathbf{1 3}}$ ou por vezes, também de tecido, e o conjunto de todas estas peças de vestuário toma o nome local de ocingwani. ${ }^{14}$

Figura 3. Aglomerado de espectadores no cimo da montanha

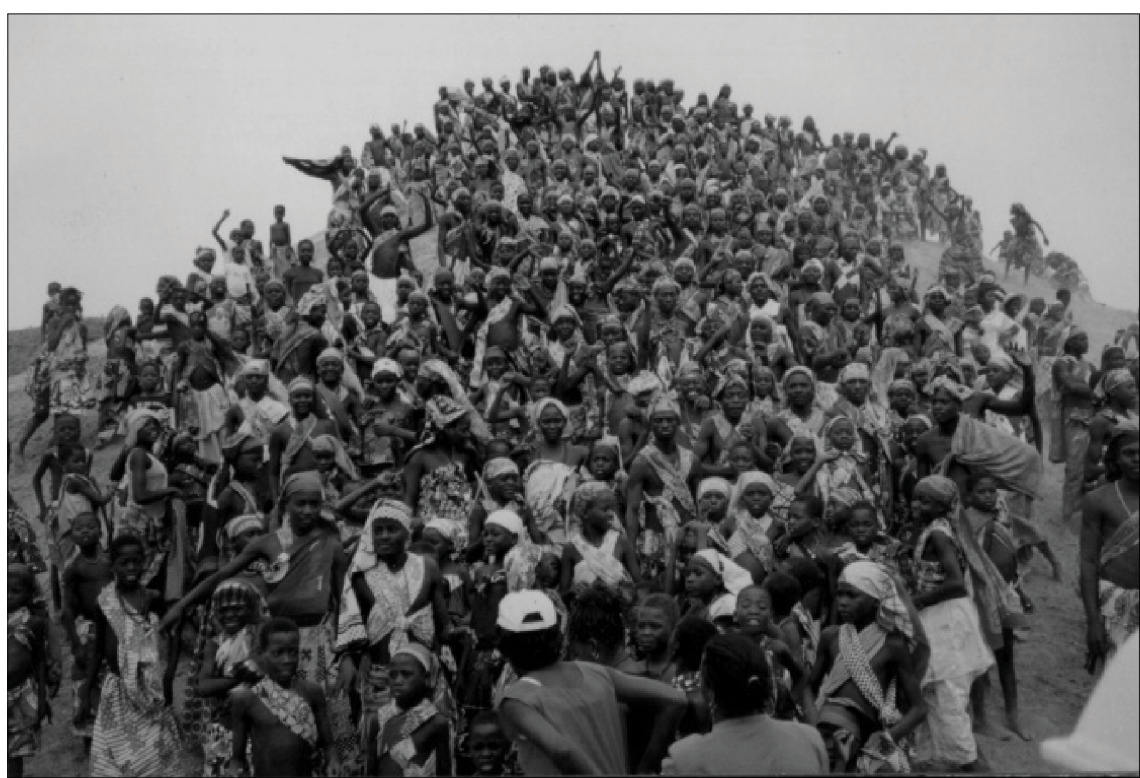

Fonte: Autor

13 Cinturão de gala, em forma de cachecol, que desce pelas pernas lateralmente até aos tornozelos.

14 Leia-se otchinguani. 
O que identifica o Mundombe dos demais grupos etnolinguísticos presentes é o porte de olomota,${ }^{\mathbf{1 5}}$ que fazem parte de todos trajes dos participantes independentemente da classe, idade ou sexo. As corres, de toda esta vestimenta, são de variante tonalidade e muito nítidas deixando os membros desta ekula dos filhos particularmente distintos pelo seu uniforme.

Do resto, um colorido como se fosse um arco-íris, em pleno sol ardente, espalha-se sobre os cimos das montanhas abaixo e pelos lados adjacentes do cemitério antigo, denominado «Cabeça do Branco ${ }^{\mathbf{1 6}}{ }^{1}$ de onde descrevemos este texto, o que visto de longe parece um jardim primaveril, com todo o tipo de flores tropicais.

Os pontos de localização, os esquemas estruturais dos grupos subdistribuídos em pelotões com lideranças, os tipos de marchas coreográficas, enfim, em tudo se diferem incluindo nas ordens, tarefas e responsabilidades. Em regime de policiamento, a ekula dos pais, distribui-se junto da ekula dos filhos e a dos mais velhos organiza-se em pequenas plenárias de vigia dentro e fora do elombe.

\section{Ponto culminante da ekula}

O juramento dos recém-iniciados antecede a exibição coreográfica designada por ekula, no final do último dia ${ }^{17}$ e torna-se o ponto culminante da realização da ekula, pois caracteriza-se pelo momento de passagem do testemunho do Homa y'Ekula pai ao Homa $y^{\prime}$ Ekula filho, transitado dos avôs, bisavôs, trisavôs, tataravôs e dos seus mais longínquos consanguíneos ligados aos olohoma vy'Akula de todos antepassados vandombe, para ser conservado e gerido segundo a vontade de todos expressa na tradição.

Neste momento, os presentes aglomeram-se no recinto do ocoto onde as mulheres, crianças e todos aqueles que não fazem parte da ekula, por não terem frequentado o ekwenje, reservam-se distantes acompanhando o ritmo da dança tradicional predominante do cerimonial que foi objecto de ensaios sistemáticos na última semana

\footnotetext{
15 O mesmo que missangas, «contas».

16 Chama-se «Cabeça do Branco» ao cemitério, por haver ali um túmulo de um colono cuja memória comunitária diz ser o primeiro a ser morto por um leão nesta região.

17 Ocorrência de 20 de Novembro de 1999.
} 
do ekwenje, agora oficialmente apresentada em público ao som de cânticos épicos exaltando as valências masculinas e do poder tradicional endógeno seguidos da musicalidade de palmas das mãos e dos pés sobre o chão sem instrumentos físicos de realce, senão, $o$ insignificante uso de bengalas.

Ainda solteiro e sem responsabilidade marital, Domingos Joaquim Singuila Malengue, nascido em 1970, segundo o que consta, agora com 29 anos de idade, herdeiro de seu pai Civela Segunda, pelo que ascendeu em cerimónia realizada em 1976, é um Mundombe de carácter tranquilo aparentemente citadino, como qualquer angolano da sua geração, não se depreendendo diferença alguma, passível de induzir o quão pesam sobre si os 23 anos de responsabilidades comunitárias de índole tradicional. Expondo-se passa o testemunho ao seu filho da perspectiva matrilinear identificado por Singuila Malengue, nome herdado do avô materno. Ladeado pelo pai social o pequeno nas vestes de Homa y'Ekula, vivencia timidamente um novo ambiente de que as atenções tornam-lhe insuficientes para captar todas as lições que tem por apreender em dois meses, desde o ocombo do ekwenje ao da ekula.

Aos 12 anos de idade, nascido em 1987, Singuila Malengue assume-se líder da mais nova geração, aguardando pelo seu primogénito para a transferência do testemunho de cuja longínqua função visualiza a trajectória da História ndombe.

O momento do juramento iniciado com uma breve alocução introdutiva, do Kesongo (cf. DAvID 1997) da mais velha geração, parado no centro do ocoto, assiste-se abafado pelo aglomerado que luta pelo acesso aos melhores lugares do cenário, acompanhando de perto, quiçá, ouvir melhor o que se diz.

O Kesongo pega no apito pendurado ao pescoço e coloca-o na boca. Soa-lhe a primeira vez, depois a segunda, a terceira e os iniciados chegados do ocombo, unindo fileiras, aglomeram-se num único lado seguindo as instruções por meio de sinais expressivos das mãos do Kesongo que orientando giram, ora para cima e para baixo, ora para os laterais, como se de um comandante de companhia militar, ou de um agente regulador de trânsito urbano se tratasse. Vendo-os organizados em três filas, uma atrás da outra, reinando a ordem e o silêncio a emergir da população espectadora, manda-os ajoelhar.

Assim inicia o juramento em língua olundombe:

«Yeveleli!... Yeveleli!...» (Escutem!... Escutem!...) 
«Catete, ${ }^{18}$ ocanu cenu "etuva"!...» (Em primeiro lugar o vosso, tomem chama-se «etuva»).

Anuncia o Kesongo que cita o nome de uma ave apanhada sã durante uma jornada de caça no ocombo. Dos vários exercícios realizados, o primeiro ser vivo encontrado na primeira jornada de caça é perseguido até que na primeira distracção caiu nas mãos de seus «predadores» sem ser sacrificado ainda que não caiba na dieta tradicional, seja ele insecto, réptil, ave, mamífero, etc. Trazido, torna-se o totem (cf. FREUD 2001) da geração servindo de baptismo aos integrantes do ocombo cujo simbolismo representa o objecto de unidade do grupo. Apesar de não se saber como se designa nas línguas mais faladas na região, a «etuva», espécie de ave de rapina de menor porte, é acusada de fonte do mau-olhado aos bebés e doravante os iniciados púberes passam a chamar-se de vakwetuva, querendo dizer «os de "etuva"» que no singular passa a ukwetuva, o mesmo que «o de "etuva"».

«Ewa!» (Sim!) - Respondem em uníssono os iniciados de joelhos no chão e costas viradas ao oriente porque em frente está a porta aberta do elombe alojando Ohoma y'Ekula mais velha e ocoto donde vêm as ordens do juramento.

«Cavali, 19 "olumbanda"!... (Em segundo lugar, «olumbanda»).

«Ewa!...»

«Catatu, ${ }^{20}$ "osipipi”!...» (Em terceiro lugar, «osipipi!...»" ${ }^{21}$.

Como se pode perceber, o Kesongo não para de mencionar os nomes distintivos da ekula em juramento.

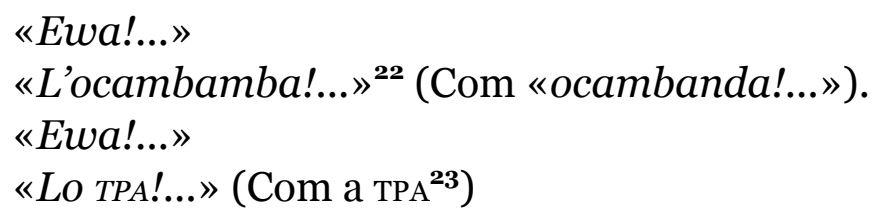

18 Leia-se tchatete, otchanu tchenu etuva.

19 Leia-se tchavali.

${ }^{20}$ Leia-se tchatatu.

21 Leia-se ossipipi.

22 Leia-se otchambamba.

23 A TPA foi designada de forma aparentemente indutiva, por haver entre a nossa equipa algum equipamento similar, muitos acreditaram tratar-se da Televisão 
«wa!...»

«A partir de hoje vocês estarão com grandes responsabilidades de conduzir os destinos deste povo ndombe, ouviram?»

«wa!...»

«Ninguém vos pode desprezar».

«Ewa!...»

«Ninguém pode matar ou maltratar "etuva”»

«wa!...»

«E “olumbanda”».

«Ewa!...»

«Se verem alguém a maltratar "etuva" vocês precisam de defendê-la!...»

«wa!...»

«Twamalã.» (Terminamos).

«wa!...»

O texto apresentado no decurso do juramento, com respostas lacónicas em uníssono, é todo da responsabilidade do Kesongo, cuja liberdade lhe confere, até que se sinta cansado e com o apito ordena o fim da sessão. Entretanto, nem tudo merece resposta da parte dos iniciados desde quanto acharem inconveniências morais ou cívicas.

29 de Fevereiro de 2000, nove dias passados do fim da ekula. $\mathrm{Na}$ expectativa de repor o presente texto aos informadores-chave e manter contactos com Ohoma y'Ekula mais velho, Singuila Malengue, sem aviso prévio, visitamos a elombe que realizou a $e k u$ la. Através da multidão encontrada no recinto recebemos a notícia confirmando o seu falecimento ocorrido aos 26 do corrente e foi a enterrar dia seguinte. Perdendo o pai, Domingos Joaquim Singuila Malengue ganhou o poder efectivo da autoridade tradicional endógena junto da nação ndombe.

198

\section{Conclusões}

No final do texto aqui descrito, sobre a ekula, cabe-nos ressaltar os seguintes aspectos:

Pública de Angola (TРА). Mas não, tratava-se apenas do nosso equipamento de recolha que foi confundido com o daquela empresa pública que, na realidade, lá não esteve. 
1. É ponto assente que a identidade ndombe do Dombe-Grande nada tem a ver com a história expansionista da sociocultura umbundu do planalto, pelo que as descrições de Ana de Sousa Santos e Ruy Duarte de Carvalho, são sustentáveis;

2. O choque da sociocultura umbundu contra a ndombe data desde o início do século Xviı, altura da fundação da colónia de Benguela, cuja perspectiva mercadológica induziu a aderência dos planálticos forçando os Vandombe a se confinarem em torno da bacia hidrográfica do vale do Kupololo até ao presente momento;

3. Devido ao elevado índice de fertilidade das bacias hidrográficas dos vales do Kupololo e de Katombela, localidades historicamente ndombe, muito cedo ocupadas pelos Ovimbundu, em resposta às dinâmicas do mercado internacional do ocidente ao interior, ambas tornaram-se propriedades coloniais implementando projectos agro-industriais, com a mão-de-obra barata do interior, fundamentada pelos planálticos habituados ao comércio e à agricultura;

4. Foi esta realidade sociocultural e etno-histórica identificada pelos estudiosos da época colonial que os induziu a concluir que tratava-se de um espaço com subsídios socioculturais e etno-históricos de índole umbundu e não helelo;

5. Entretanto, para além do mercado pré-colonial dos séculos XVII a xIx e da implementação dos projectos coloniais agro-industriais do século $\mathrm{xx}$, que determinaram o ambiente indutivo acima descrito, as consequências da guerra contra o sistema colonial desde a década de 1960, e das desavenças pós-independência de 1974 a 2002, constituem o conjunto de dinâmicas que têm alterado sobremaneira a realidade ndombe a favor do predomínio dos valores relativos aos Ovimbundu.

\section{Referências bibliográficas}

\section{Altuna Padre Raul Ruiz de Asúa}

1985, Cultura tradicional Bantu. Apresentação de Dom Eduardo André Muaca. Prefácio do Autor. Luanda, Secretariado Arquidiocesano de Pastoral.

ArJago, ver Gomes Armindo Jaime, infra

Chambers R.

1995 (2. ${ }^{a}$ edição), Desenvolvimento rural, fazer dos últimos os 
primeiros. Luanda, ADRA - Acção para o Desenvolvimento Rural e Ambiente.

\section{Carvalho Ruy Duarte de} 1997, Aviso à navegação. Olhar sucinto e preliminar sobre os pastores Kuvale com um relance sobre as outras sociedades agropastoris do Sudoeste de Angola. Luanda, INALD - Instituto Nacional do Livro e do Disco [«Estudos e documentos: Ensaio»; 22].

CREMA Roberto

[s. d.], Mitos e ritos. Breve resenha. Disponível em <http://www. dialogosdoser.com/artigos/roberto_artigos/artigoo6. pdf $>$

DAvid Raul

1997, Da justiça tradicional nos Umbundu. Luanda, INALD Instituto Nacional do Livro e do Disco.

DuFf Padre Frederico

1945, «Circuncisão», Portugal em África. Revista de Cultura Missionária, 2. ${ }^{\mathrm{a}}$ série, ano I.

ELIADE Mircea 2006, O sagrado e o profano. A essência das religiões. Tradução de Rogério Fernandes. Lisboa, Edição Livros do Brasil [«Vida e cultura»; 62].

\section{Estermann Padre Carlos}

1944, «A festa da puberdade em algumas tribos de Angola Meridional», Portugal em África. Revista de cultura missionária, 2 . $^{\text {a }}$ série, ano I, n. ${ }^{\circ} 6$.

[1983, "A festa da puberdade em algumas tribos de Angola Meridional», in Padre Carlos Estermann, Etnografia de Angola (Sudoeste e Centro). Colectânea de artigos coligidos por Geraldes Pereira, c.s.sp.; apresentação de Manuel Viegas Guerreiro. Lisboa, Instituto de Investigação Científica Tropical, pp. 193-205].

1949, «Etnologia Angolana em três livros recentes», Portugal em África. Revista de cultural missionária, $2 .^{\mathrm{a}}$ série, ano vi, n. ${ }^{\circ} 31$. [1983, «A Etnologia Angolana em três livros recentes», in Padre Carlos Estermann, Etnografia de Angola (Sudoeste e Centro). Colectânea de artigos coligidos por Geraldes Pereira, C.S.Sp.; apresentação de Manuel Viegas Guerreiro. Lisboa, Instituto de Investigação Científica Tropical, pp. 407-419].

FREUD Sigmund

1950, Totem e Tabu. Alguns pontos de concordância entre a vida psíquica dos selvagens e a dos neuróticos. Tradução de Leopoldina Almeida; revisão de Professor Pedro Luzes. Lisboa, Relógio d’Água [«Imago»]. 
Gomes Armindo Jaime

1999, Epata L'Usoma. Apontamentos etno-históricos ovimbun$d u$. Lobito, NNARP.

2002, Os sobas. Apontamentos etno-históricos sobre os Ovimbundu de Benguela. Benguela.

2007, As civilizações lacustres das margens do Kupololo. Prefácio de Maria Alice dos Santos Cabral. Benguela, KAT - Empreendimentos e Consultoria, Lda. [«Estudos»; 2].

Gonçalves António Custódio

1984, "Simbolização do processo político e dinamismo sociocultural numa sociedade tradicional: Abordagem histórica e sistémica», Análise Social, vol. xx, n. ${ }^{\circ}$ 84, pp. 663-683

2001, «Rituais tradicionais de solidariedade: Religião e tensões entre finitude e infinitude», in Luís A. O. Ramos et al. (org.), Estudos em homenagem a João Francisco Marques. Porto, Faculdade de Letras da Universidade do Porto, volume II, pp. 9-17. Disponível em <htpp://ler.letras.up.pt/uploads/ficheiros/2815. pdf $>$

Guebe António

2003, O que eu aprendi no Otchoto. Luanda, Editorial Kilombelombe [«Cruzeiro do Sul»; 1].

MARTinez João Flávio

2007, Culto aos antepassados. Disponível em <http://www. cacp.org.br/estudos/artigo.aspx>

SANTos Ana de Sousa

1963, Catálogo da Exposição de Miniaturas Angolanas. Luanda, Outubro de 1963. Edição de Autor, subsidiada pelo IICA - Instituto de Investigação Científica de Angola.

1965, Exposição de «Miniaturas Angolanas» de Ana de Sousa Santos. Palácio Galveias, Campo Pequeno, 6 de Maio de 1965. Apresentação de António Vitorino França Borges. Prefácio da Autora. Lisboa, Câmara Municipal de Lisboa.

SANTos Eduardo dos

1962, Sobre a religião dos Quiocos. Lisboa, Junta de Investigações do Ultramar [«Estudos, ensaios e documentos»; 96]. 1969, Religiões de Angola. Lisboa, Junta de Investigação do Ultramar. 
Title: Fundamentals of ekula in traditional Mundombe power

\begin{abstract}
This article was written from a summary of oral data collected between 1997 and 2005 and seeks to analyze the sociocultural and ethno-historical ndombe reality in Dombe-Grande, a town located in the coastal south of Benguela. In the beginning, the collection of materials in the fieldwork had as objective to know (with a Freirean perspective) the reality in which the nonformal educational methodologies were processed. At the same time, from the ethnological point of view, it try to better identified the Mundombe taking into account the old assumption pointed out by distinguished scholars and researchers, whose proposals of classification emphasized this community in the Ovimbundu chain. The exception to the rule of this view is due to Ana de Sousa Santos $(1963,1965)$ and Ruy Duarte de Carvalho (1997), who argued that this was a sociocultural complex of the Helelo complex, although, to be confirmed. In order to assure this thesis, the present text describes a traditional ceremony about the ekula, a political-religious institution observed in 1999, without being able to support it with bibliographical references of previous studies on this subject.
\end{abstract}

Keywords: Traditional endogenous institution, ekula, Ohoma y'Ekula, socio-cultural complex, Helelo sociocultural complex, Ovimbundu chain

\title{
Armindo Jaime Gomes
}

É mestre em Administração escolar (2010) pela Universidade de Évora, Évora, Portugal e licenciado em Ensino de História (1996) pelo Instituto Superior de Ciências da Educação (ISCED) do Lubango, província da Huíla. Actualmente é docente da cadeira de História de Angola na Academia Militar do Exército em Benguela. Enquanto investigador independente publicou entre outros os materiais seguintes: Epata L'Usoma. Apontamentos etno-históricos ovimbundu (2000); Os Sobas. Apontamentos etno-históricos dos Ovimbundu de Benguela (2003); As civilizações lacustres nas margens do Kupololo. Ensaio etno-histórico sobre Benguela (2007). Além das múltiplas funções de investigador, docente e consultor, é escritor membro da União dos Escritores Angolanos (UEA), cujos trabalhos assina com o anagrama Arjago, tendo publicado: Crepúsculo matutino. Poesia (1990); Noites por dia. Poesia (1998), Premio Literário António Jacinto. Figura na obra colectiva Todos os sonhos. Antologia da poesia moderna, obra com a qual a UEA comemorou 30 anos de literatura em Angola.

[e-mail: arjago_kat@yahoo.com.br]

[e-mail: cacul.k@gmail.com] 